\title{
NOTAS SOBRE NARRATIVAS AUTOBIOGRÁFICAS DE AUTORES SURDOS ${ }^{1}$ NOTES ON AUTOBIOGRAPHICAL NARRATIVES BY DEAF AUTHORS
}

https://doi.org/10.46551/2179679320200006

Paulo Roberto Tonani do Patrocínio Universidade Federal do Rio de Janeiro

paulotonani@gmail.com iD tttps://orcid.org/0000-0003-0436-2490

RESUMO: O presente artigo analisa narrativas de natureza autobiográfica publicadas em língua portuguesa assinadas por autores surdos brasileiros com o objetivo de investigar os modos de autorrepresentação da diferença surda, colocando em foco a heterogeneidade de tal experiência. O referencial teórico adotado para dar materialidade ao objetivo traçado dialoga com pesquisas sobre narrativas autobiográficas e outras formas de escrita de si, além das contribuições de pesquisadores vinculados ao campo dos Estudos Culturais e em especial dos Estudos Surdos.

PALAVRAS-CHAVE: Surdos; Autorrepresentação; Autobiografias; Diferença; Deficiência.

ABSTRACT: This article analyses narratives of autobiographical nature published in Portuguese and signed by Brazilian deaf authors, with the aim of investigating the modes of self-representation of the deaf difference, placing the heterogeneity of such experience in focus. The theoretical framework adopted in order to provide materiality to the objective outlined engages with researches on autobiographical narratives and other forms of writings of the self, besides the contributions of scholars associated to the field of Cultural Studies, particularly of the Deaf Studies.

KEYWORDS: Deaf; Self-representation; Autobiographies; Difference; Disability.

Pensar narrativas autobiográficas produzidas por sujeitos surdos é estar diante de relatos formados a partir de uma experiência ontológica intrinsecamente ligada à materialidade de um corpo. A história nos revela as muitas interdições sofridas por esse corpo. Seja pelas inúmeras tentativas de cerceamento e proibição do uso de uma língua gesto-visual ou pelo seu completo isolamento. $\mathrm{O}$ corpo do sujeito surdo ainda ocupa o incômodo lugar de objeto de discursos

\footnotetext{
${ }^{1} \mathrm{O}$ presente artigo apresenta parte dos resultados da pesquisa "A representação da diferença surda na literatura brasileira", financiada pela Fundação de Amparo à Pesquisa do Estado do Rio de Janeiro - FAPERJ, por meio do Programa Jovem Cientista do Nosso Estado. É igualmente necessário registrar o meu agradecimento à Thaici Lopes Marinho pela contribuição no levantamento bibliográfico das obras que compõe o corpus de minha análise e pelas sugestões críticas ofertadas, muito obrigado.
} 
normativos baseados em conceitos estéreis, formados pela modernidade ocidental. Penso que as muitas metáforas que envolvem a experiência surda são reveladoras do preconceito e do desconhecimento.

A surdez é tida como alienação, descompasso e isolamento, estas são algumas das ideias mais negativas que podem ser atribuídas ao surdo. Isso sem mencionar a forma mais pejorativa de classificação e nomeação destes sujeitos: surdo-mudo. Esta é, em essência, a expressão mais negativa que podemos utilizar para denominar um surdo. Além da perda de sua audição, retiramos dele toda e qualquer forma de expressão. Nesta definição não existe nenhuma forma de subjetivação ou agência. Em síntese, resta-nos apenas afirmar que a experiência surda não é uma metáfora. A experiência surda não pode ser uma metáfora do isolamento.

"A surdez não é um tema da audiologia, mas de epistemologia"². A definição é de Owen Wrigley e sintetiza uma complexa disputa teórica que coloca em pauta definições da surdez em diferentes campos disciplinares, resultando em tratamentos e concepções distintas para a mesma. A assertiva propõe um verdadeiro deslocamento teórico ao recusar de forma explícita um tratamento médico terapêutico para a surdez e a define enquanto um paradigma epistemológico. Contudo, o autor da frase não está apenas atento a emergência de uma nova concepção da experiência surda, a breve sentença busca identificar um sentido político neste exercício de deslocamento, conforme evidencia Tomaz Tadeu da Silva, acerca da mesma passagem:

"Epistemologia" não é compreendida aqui no sentido da filosofia ou da pedagógica do desenvolvimento, mas no sentido político que Ihe deu, sobretudo, [Michel] Foucault. "Epistemologia" remete, nesta concepção, às condições entre conhecimento e poder ${ }^{3}$.

Em outras palavras, a surdez é lida enquanto reflexo e efeito primeiro de configurações discursivas de saber-poder que resultam em representações que transitam entre um modelo médico terapêutico - baseado em uma perspectiva que nomeia o sujeito surdo enquanto deficiente e lança mão de estratégias e recursos clínicos que almejam a sua reabilitação - e um modelo 
socioantropológico - fundado em uma perspectiva culturalista inspirada nos Estudos Culturais que nomeia a surdez enquanto uma diferença étnico-linguista ${ }^{4}$ que constitui uma cultura própria, a Cultura Surda. Tais modelos são antagónicos, produzem representações e definições próprias para a experiência surda e, principalmente, coexistem. Não estamos lidando com uma linearidade temporal sucessiva de discursos que possa ser compreendida como a formação de um determinado quadro evolutivo. Não há uma suplementação de modelos ou mesmo uma substituição. Mesmo que o modelo socioantropológico tenha sido estruturado a partir da recusa medicalização da surdez, o modelo médico terapêutico, com sua perspectiva clínica, ainda se faz presente em diferentes campos disciplinares.

Nas últimas décadas, observamos a difusão, no Brasil, de uma concepção socioantropológica da surdez que impacta de modo claro às formas de representação e nomeação do sujeito surdo ao utilizar como ponto de ancoragem suas particularidades linguísticas e identitárias. De inspiração pós-estruturalista e lançando mão de uma série de conceitos e pressupostos teóricos dos Estudos Culturais, essa concepção forma uma nova episteme e edifica um horizonte conceitual de inspiração culturalista que nomeia a surdez enquanto uma diferença étnico-linguística e forma um novo campo de estudos, que por vezes é nomeado como Estudos Surdos, Estudos Culturais Surdos ou Estudos da Educação de Surdos.

Um dos resultados imediatos da emergência desta nova episteme é a recusa do conceito deficiência enquanto recurso representacional da diferença surda e, paralelo a isto, assistimos a crítica a uma concepção clínica da surdez, que concebe o surdo enquanto sujeito a ser reabilitado por terapias realizadas por profissionais da área de fonoaudiologia e/ou pelo uso de tecnologias inclusivas,baseadas no uso aparelhos auditivas na tentativa de potencializar resíduos auditivos ou em intervenções cirúrgicas para a realização de implantes na cóclea.

No entanto, é importante ressaltar que a representação da surdez e do sujeito surdo é um campo em disputa e que a emergência de uma área disciplinar

\footnotetext{
4 A expressão é de César Augusto de Assis Silva, no livro Cultura surda: agentes religiosos e a construção de uma identidade. SILVA, 2012.
} 
que busca o tratamento deste sujeito a partir de uma concepção socioantropológica não significa que os discursos médicos e clínicos que orientavam de forma majoritária as representações da surdez tenham sido obliterados. Ao contrário, a perspectiva clínica que busca a reabilitação do sujeito surdo, lido e compreendido sempre enquanto em uma perspectiva patológica de um deficiente auditivo, ganhou ainda maior impulso na última década com os avanços na área médica que resultaram na popularização de cirurgias de implante coclear. No interstício entre o modelo socioantropológico e o clínico, não está apenas uma disputa vocabular que nos solicita a escolha entre os termos surdez e deficiência auditiva, mas, principalmente, formas de conceber e representar sujeitos. Afinal, como observa Ana Dorziat,

o desenvolvimento de reflexões sobre o grupo de pessoas denominadas surdas requer, necessariamente, considerações mais apuradas sobre em quais bases conceituais está sendo construída a identidade desse grupo ${ }^{5}$.

$\mathrm{Na}$ reflexão da pesquisadora, está presente a base de nosso argumento teórico que busca conceber a surdez e o sujeito surdo enquanto reflexo de representações e definições formadas a partir de determinadas configurações discursivas de saber-poder. Ao propor o conceito de diferença enquanto elemento definidor do sujeito surdo, além da controversa recusa da noção de deficiência como categoria definidora - recusa que ainda precisa ser melhor discutida em uma dimensão conceitual e política - os Estudos Surdos buscam conceber a surdez fora de uma concepção patológica que localiza apenas a necessidade de reabilitação do surdo.

Além disso, é importante dimensionar que a mudança epistemológica proporcionada pela perspectiva culturalista instaura um modelo de educação bilíngue para os surdos contrastando os outros modelos já existentes: o oralismo e a comunicação total. É nomeada como oralismo uma filosofia pedagógica que tinha como cerne da educação de surdos o ensino da oralidade a partir de sessões terapêuticas que visavam a reabilitação do sujeito surdo. Dessa forma, tal filosofia não visava a oferta de métodos de transmissão do conhecimento, e

\footnotetext{
${ }^{5}$ DORZIAT, 2009, p. 15.
} 
sim se ocupava do ensino da articulação oral, leitura labial e do aproveitamento de resíduos auditivos, conforme observa César Augusto de Assis Silva, em Cultura surda: agentes religiosos e a construção de uma identidade ${ }^{6}$. Em outra perspectiva, o método da comunicação total representa uma prática pedagógica da educação de surdos que utiliza diversos modos de comunicação no processo de ensino aprendizagem do sujeito surdo, como

a língua de sinais, a oralidade, a leitura labial, o desenho, a mímica, o teatro, a escrita e quaisquer outros modelos de comunicação possível em sala de aula, porque o importante passa a ser o conteúdo a ser transmitido, e não mais o modo ${ }^{7}$.

É importante observar que a defesa do modelo de educação bilíngue para surdos emerge em diálogo com as produções acadêmicas da área de linguística sobre a Língua Brasileira de Sinais (Libras) e, principalmente, em decorrência do engajamento de associações e federações de surdos em favor da afirmação da Libras como língua natural, movimento este que culminou no dispositivo jurídico recente que reconhece a Libras como uma língua legítima no interior da nação por meio da Lei Federal 10.436/2002. A referida Lei apresenta em seu primeiro artigo a materialidade de um desejo de diferentes atores que atuaram em favor da educação de surdos e na pesquisa e ensino de Libras ao afirmar que

Art. 1o É reconhecida como meio legal de comunicação e expressão a Língua Brasileira de Sinais - Libras e outros recursos de expressão a ela associados.

Parágrafo único: Entende-se como Língua Brasileira de Sinais Libras a forma de comunicação e expressão em que o sistema linguístico de natureza visual-motora, com estrutura gramatical própria, constituem um sistema linguístico de transmissão de ideias e fatos, oriundos de comunidade de pessoas surdas do Brasil ${ }^{8}$.

O reconhecimento da Libras como língua natural - conceito linguístico que define que as línguas emergem de forma espontânea em uma comunidade de falantes - oferece à língua de sinais o mesmo estatuto linguístico que qualquer língua oral natural recebe. Afinal, no argumento dos linguistas que se dedicam ao

\footnotetext{
${ }^{6}$ SILVA, 2012.

${ }^{7}$ SILVA, 2012, p. 36.

8 BRASIL, 2002
} 
estudo da Libras, esta emergiu de comunidades de sujeitos surdos e são passíveis de análise linguística em diversos planos: sintático, morfológico, fonológico e pragmático. Além disso, é igualmente importante ressaltar o trabalho do linguista norte-americano William $\mathrm{C}$. Stroke enquanto referência nos estudos de diferentes línguas de sinais e ao mérito de demonstrar, "pela análise dos sinais da American Sign Language (ASL), que as línguas de sinais eram também naturais, uma vez que partilhavam com as linguais orais os mesmos princípios de estruturação"'. No âmbito brasileiro, Lucinda Ferreira Brito é autora de estudos pioneiros na área e que influenciaram uma série de pesquisadoras e pesquisadores que se dedicaram aos estudos da Libras, como Ronice Quadros, Lodenir Karnopp e Tanya de Amara Felipe de Souza, para citar alguns dos principais estudos sobre a Língua Brasileira de Sinais.

A breve narrativa acerca do processo de constituição de uma concepção culturalista da experiência surda evidencia que estamos diante de um tensionamento das formas de representar o sujeito surdo, tornando claro que a experiência da surdez não pode ser lida enquanto um dado homogêneo. A localização deste ponto de clivagem entre os discursos da diferença surda - de um lado o modelo clínico e em um ponto diametralmente oposto o modelo socioantropológico - permitirá uma leitura contrastante entre as representações derivadas destes discursos, constituindo a formação de um olhar prismático sobre o sujeito surdo. Ao lançar um olhar crítico para as narrativas de natureza autobiográficas assinadas por autores surdos, o presente artigo tem como objetivo contribuir para o debate sobre as representações e autorrepresentações deste grupo.

No processo de levantamento bibliográfico do corpus de análise foram localizadas diferentes narrativas autobiográficas de autoria surda, revelando a potencialidade deste objetivo e, principalmente, a urgência na produção de uma análise crítica acerca destes discursos. Em uma investigação preliminar foram localizadas 7 narrativas autobiográficas publicadas em língua portuguesa e assinadas por autores surdos brasileiros, sendo elas: Surdez - silencio em voo de borboleta, de Patrícia Rodrigues Witt ${ }^{10}$; Ser surda: história de uma vida para

\footnotetext{
${ }^{9}$ SILVA, 2012, p. 34.

${ }^{10}$ WITT, 2013.
} 
muitas vidas, de Sílvia Andreis-Witkoski e Rosani Suzin Santos ${ }^{11}$; Despertar do silêncio, de Shirley Vilhalva ${ }^{12}$, Crônicas da surdez ${ }^{13}$ e Novas crônicas da surdez epifanias do implante coclear ${ }^{14}$, de Paula Pfeifer; Bela do silêncio, de Brenda Costa $^{15}$ e Mãos fazendo história, organizado por Sabine Antonialli Arena Vergamini ${ }^{16}$. Por razões metodológicas, nossa análise irá privilegiar narrativas assinadas por autores surdos brasileiros, pois nosso objetivo é analisar como se dá o impacto da emergência de uma concepção socioantropológica da experiência surda nas representações de sujeitos surdos na literatura brasileira. Dessa forma, o conhecido relato da atriz francesa Emanuelle Laborit, O grito da gaivota $^{17}$, não compõe o corpus de análise. No entanto, reconhecemos a amplia circulação da narrativa de Laborit na comunidade surda, seu impacto no processo de produção das identidades surdas e, principalmente, a sua influência sobre as narrativas autobiográficas de surdos brasileiros. A partir deste mesmo critério, a narrativa Como é ser surdo, de Vera Strnadová ${ }^{18}$, também não fará parte do corpus de análise por ser uma obra assinada por uma autora tcheca.

Faz-se necessário tecer comentários sobre a própria natureza destes discursos e acerca do lugar fronteiriço que os mesmos ocupam ao transitarem entre uma forma de escrita de si que congrega elementos do que convencionamos nomear como textos autobiográficos e recursos testemunhais que se fundam no depoimento de uma história de vida. Afinal, o sujeito autoral que assina tais narrativas ocupa um lugar ontológico oposto ao individualismo autotélico que funda as narrativas autobiográficas que cumprem determinados preceitos do gênero formado na modernidade. É possível observar que o desnudamento da experiência subjetiva do sujeito surdo não está fixada apenas no processo de formação de self e no atravessamento das fronteiras entre público e privado. Nas narrativas analisadas o processo de constituição do sujeito ocorre na afirmação de um traço ontológico que não apenas o nomeia, mas, igualmente, o define. $O$ ato de narrar a experiência surda promove a produção de um texto

\footnotetext{
${ }^{11}$ WITKOSKI e SANTOS, 2013.

${ }^{12}$ VILHALVA, S/D

${ }^{13}$ PFEIFER, 2013.

${ }^{14}$ PFEIFER, 2015.

${ }^{15}$ COSTA, 2008.

${ }^{16}$ VERGAMINI, 2003.

17 LABORIT, 1998.

18 STRNADOVA, 2000.
} 
Programa de Pós-graduação em Letras/Estudos Literários da Unimontes v.21, n.1, 2020. ISSN: 2179-6793

que se estrutura a partir deste dado essencial e formador. Não se trata de uma oposição aos elementos formadores de uma tradição discursiva baseada na exteriorização do eu e que constituíram um espaço de autorreflexão decisivo para a consolidação do individualismo como um dos traços típicos do Ocidente, conforme observou Leonor Arfuch, em O espaço autobiográfico: dilemas da subjetividade contemporânea ${ }^{19}$. Os relatos de vida formados a partir da experiência surda instauram uma particularidade outra, que incide na constituição de um traço definidor do sujeito surdo e sua filiação a uma coletividade maior. $O$ ato de narrar a experiência surda, por si só, evidencia a afirmação de uma identidade baseada na diferença.

O caráter identitário destas narrativas de autoria surda nos permite observar traços de semelhança entre estas experiências discursivas e textos do chamado testemunho hispano-americano. Em ambos os casos é evidenciada a recusa de um individualismo burguês para a construção de uma subjetividade outra, fixada na afirmação de uma diferença ontológica e irredutível. Afinal, nos textos do testemunho hispano-americano, conforme analisa João Camillo Penna $^{20}$, a partir dos relatos de vida de sujeitos subalternizados é encenada a formação de uma autoconsciência que consiste na interpelação do sujeito autocentrado ocidental sob a perspectiva de um modelo latino-americano de política identitária. Nos textos aqui analisados, seja em uma narrativa formada em uma clave clínica que se estrutura a partir da descoberta de um diagnóstico conforme narram Paula Pfeifer e Brenda Costa - ou em uma perspectiva socioantropológica tendo como pano de fundo a afirmação de uma identidade surda - como podemos ler em Shirley Vilhalva, Rosani Suzin Santos e Patrícia Rodrigues Witt - o traço de unidade dos textos analisados é a localização da experiência surda. Ainda que seja fixada na afirmação da individualidade do sujeito que escreve - e a instância autoral não cessa de nos lembrar esse caráter intransferível - as narrativas de autores surdos não reproduzem o marco fundador da subjetividade moderna de um Bildungsroman ou de uma autobiografia de um sujeito exemplar, estas se estruturam a partir do exame da experiência do sujeito em face a sua característica ontológica e narra a construção de uma subjetividade

\footnotetext{
${ }^{19}$ ARFUCH, 2010.

${ }^{20}$ PENNA, 2003.
} 
marcada pela diferença, seja ela lida enquanto uma dimensão cultural ou clínica.

A existência de uma espécie de fronteira na própria definição da experiência surda, que transita entre definições clínicas e socioantropológicas, surge como impeditivo do uso do conceito de patografia enquanto recurso teórico para leitura destas narrativas. De acordo com Ana Cristina Bohrer Gilbert, o termo patografia foi cunhado por Anne Hunsaker Hawkins ${ }^{21}$ para definir

[...] um gênero de narrativas na qual uma experiência profundamente traumática e destrutiva relacionada ao adoecimento é relatada, bem como as alternativas encontradas para com ela conviver e de algum modo transformá-la em uma experiência restauradora ${ }^{22}$.

As narrativas aqui analisadas se aproximam em alguns pontos das patografias estudadas por Hawkins, principalmente devido o desejo manifesto de uma função restauradora que possibilitará aos leitores, principalmente para leitores que compartilham da experiência surda, a efetivação de uma espécie de superação e/ou reconhecimento da surdez. No entanto, a maior distinção entre as narrativas analisadas por Hawkins e as que compõem o objeto deste estudo se fixa na minha recusa ao ofertar um tratamento unicamente clínico a tal experiência, creio que tais relatos congregam aspectos de uma subjetividade minoritária que se forma a partir do reconhecimento de uma particularidade audiológica. As narrativas, nesta perspectiva, apresentam uma estrutura semelhante que se baseia em primeiro lugar na narração da descoberta do diagnóstico clínico da surdez ainda na primeira infância. A emergência desse dado revela a produção da consciência de ser diferente a partir de uma dimensão audiológica e, por conseguinte, da língua que se usa. Por apresentarem uma estrutura linear e causal, esse episódio é sempre um dos primeiros relatos a serem apresentados nas narrativas. No entanto, tal relato não é construído a partir da memória do próprio sujeito que narra, mas pela memória construída a partir da narrativa feita por familiares acerca do episódio, quase sempre os pais. "Impacto atordoante da notícia" 23 , "o susto foi tão grande" 24 e "a cara inchada de

\footnotetext{
${ }^{21}$ HAWKINS, 1999.

22 GILBERT, 2012, p. 90.

${ }^{23}$ WITT, 2013, p. 20.

${ }^{24}$ SANTOS, 2013, p. 18.
} 
Programa de Pós-graduação em Letras/Estudos Literários da Unimontes v.21, n.1, 2020. ISSN: 2179-6793

tanto chorar"25 são expressões que são utilizadas para dimensionar a descoberta do diagnóstico clínico da surdez. O desequilíbrio causado pelo diagnóstico é o ponto de partida para a edificação de uma narrativa pontuada por um relato de superação, com uma retórica que coloca em relevo as conquistas do sujeito. Novamente estamos diante de uma dualidade, de um jogo de opostos que coloca em confronto visões e concepções acerca de uma mesma experiência que ao menos pode ser nomeada como semelhante. Ao cotejarmos os relatos aqui citados é possível afirmar que a materialidade dos corpos surdos em face a descoberta de suas particularidades intrínsecas pode ser compreendida a partir de registros epistemológicos distintos que apontam para percursos formativos próprios e visões de mundo antagônicas. Ainda que o ponto de partida seja o mesmo, o resultado deste percurso narrativo que se baseia na investigação da experiência surda aponta para uma heterogeneidade de formas.

Narrar a experiência surda não significa, necessariamente, narrar 0 silêncio. Ainda que a emergência de uma perspectiva socioantropológica ofereça como forma de ancoragem conceitual a ideia de diferença, de modo sistemático as narrativas autobiográficas assinadas por autores surdos passam por evidenciar a noção de silêncio enquanto elemento caracterizador desta experiência. $O$ resultado primeiro deste exercício é a revisitação a uma concepção da experiência surda sob o prisma da deficiência. Bela do silêncio, de Brenda Costa $^{26}$, talvez seja o maior exemplo deste modelo de narrar. A autora, uma exmodelo internacional, constrói toda a materialidade de seu relato a partir da ideia do silêncio e da impossibilidade de expressão oral. O silêncio, lido enquanto falta, surge como elemento constituinte da experiência. Patrícia Rodrigues Witt, em Surdez, silêncio em voo de borboleta, também demarca o silêncio enquanto traço formador da experiência surda, ainda que a autora compartilhe de uma perspectiva socioantropológica para narrar a surdez: "ninguém suspeitava do mundo do silêncio que rodeava"27.

Pensar a experiência surda a partir da noção de silêncio, coloca-nos diante da ideia de vazio e ausência, principalmente por evidenciar o traço patológico que se liga ao aparelho auditivo. O mecanismo representacional diametralmente

\footnotetext{
${ }^{25}$ PFEIFER, 2013, p. 25.

${ }^{26}$ COSTA, 2008.

${ }^{27}$ WITT, 2013, p. 20.
} 
oposto à ideia do silêncio seria a afirmação da visualidade da experiência surda $e$ o uso de línguas gesto-visuais enquanto recurso comunicacional. A coletânea Mãos fazendo história, organizado por Sabine Antonialli Arena Vergamini ${ }^{28}$ é o exemplo mais profícuo desta estratégia de representação. O volume reúne 14 depoimentos de surdos que foram colhidos em Libras e traduzidos para língua portuguesa, compondo um verdadeiro mosaico de experiências de sujeitos surdos. A partir do uso explícito de uma retórica da superação, a publicação emerge enquanto um dispositivo de subjetivação de novas identidades surdas.

Além disso, a publicação de Mãos fazendo história também revela outro aspecto importante que atravessa parte das narrativas aqui analisadas, a questão linguística e o domínio do registro formal da escrita pelos sujeitos surdos. A opção pelo registro do depoimento em Libras e a consequente tradução deste para língua portuguesa nos coloca diante da particularidade linguística destes sujeitos. Soma-se a isto a atuação da organizadora do volume enquanto gestora dos depoimentos, cumprindo um papel de uma espécie de porta-voz dos autores dos relatos. Sabine Vergamini é responsável não apenas pela coleta e organização do volume, mas, principalmente, pelo processo de tradução dos mesmos. Contudo, a forma discursiva adotada é o discurso indireto que resulta no posicionamento da gestora do depoimento no interstício entre o sujeito do testemunho e o leitor. Procedimento semelhante é realizado por Sílvia Andreis-Witkoski, em Ser surda, diante do depoimento de Rosani Suzin Santos. Especialista em educação de surdos, Andreis-Witkoski atua como gestora e tradutora do depoimento de Rosini Santos, pedagoga surda. Em ambos os casos, estamos diante de duas intelectuais que elaboram estratégias que visam a constituição de subjetividades surdas tradicionalmente excluídas, principalmente devido suas particularidades linguísticas. O resultado deste empreendimento crítico é o desejo de conceber a surdez em sua própria contingência e a partir de suas autorrepresentações.

O breve percurso de análise aqui apresentado é apenas um primeiro exercício exploratório que objetiva investigar a produção de uma nova discursividade sobre a diferença surda, que concebe o sujeito surdo enquanto pertencente a uma minoria étnico-linguista, e analisar os reflexos desta nova epistemologia nas formas de representação deste grupo social. A localização

${ }^{28}$ VERGAMINI, 2003. 
deste ponto de clivagem nos discursos da diferença surda nos permite observar o tensionamento entre as representações derivadas destes discursos, constituindo a formação de um olhar prismático sobre o sujeito surdo.

\section{Referências}

ANDREIS-WITKOSKI, Sílvia; SANTOS, Rosani Suzin. Ser surda: história de uma vida para muitas vidas. Curitiba: Juruá Editora, 2013.

ARFUCH, Leonor. $O$ espaço biográfico. Dilemas da subjetividade contemporânea.Tradução de Paloma Vidal. Rio de Janeiro: EdUERJ, 2010

COSTA, Brenda. Bela do silêncio. (com a colaboração de Judith Carraz). Tradução Mariana Echalar. São Paulo: Martins, 2008.

DORZIAT, Ana. O outro da educação: pensando a surdez com base nos temas identidade/diferença, currículo e inclusão. Petrópolis: Vozes, 2009.

GILBERT, Ana Cristina Bohrer. Vértice do impensável: um estudo de narrativas em síndrome de Down. Rio de Janeiro: Editora da FIOCRUZ, 2012. Coleção Criança, Mulher e Sociedade.

KARNOPP, Lodenir; KLEIN, Madalena; LUNARDI-LAZZARIN, Márcia Lise. Cultura surda na contemporaneidade:negociações, intercorrências e provocações.Canoas: Editora ULBRA, 2011.

LOPES, Maura Corcini. Surdez \& educação. Belo Horizonte: Autêntica, 2011. 2ª Edição revista e ampliada.

LUNARDI-LAZZARIN, Márcia Lise. "Os discursos da diferença no contexto das políticas de inclusão: a normalidade no detalhe". In: TREVISAN, Amarildo Luiz; TOMAZETTI, Elisete M.; ROSSATO, Noeli Dutra (Orgs). Diferença, cultura e educação. Porto Alegre: Sulina, 2010.

LUZ, Renato Dente. Cenas surdas: os surdos terão seu lugar no coração do mundo? São Paulo: Parábola, 2013

MARINHO, Thaici Lopes. Privação de Língua:uma análise a partir de narrativas Surdas, aquisição e importância da Língua de Sinais. 2019. 21 f. Trabalho de Conclusão de Curso (Especialização) - Instituto Nacional de Educação de Surdos - INES, Rio de Janeiro, 2009 (mimeo).

MARTINS, Bruno Sena e FONTES, Fernando. Deficiência e emancipação social:Para uma crise da normalidade.Coimbra: Almedina/CES, 2016.

PENNA, João Camillo. "Este corpo, esta dor, esta fome: notas sobre o testemunho hispano-americano". In: SELIGMANN-SILVA, Márcio. História, memória, literatura:O testemunho na Era das Catástrofes. Campinas: Editora da Unicamp, 2003.

PERLIN, Gladis T. T.. "Identidades surdas". In: SKLIAR, Carlos (Org.). A surdez: um olhar sobre as diferenças. Porto Alegre: Editora Mediação, 2013, 6ª Edição, pp.51-73.

"As Identidades Surdas". Revista da FENEIS, Ano IV, n. 14 abr./jun. de 
2002.

O ser e estar sendo surdos: alteridade, diferença e identidade. 2003. 156 f. Tese (Doutorado em Educação) - Programa de Pós-Graduação em Educação. Universidade Federal do Rio Grande do Sul, Porto Alegre, 2003.

SACKS, Oliver. Vendo vozes: uma narrativa ao mundo dos surdos. Tradução de Laura Teixeira Motta. São Paulo: Companhia das Letras, 2010.

SILVA, Tomaz Tadeu da. "A política e a epistemologia do corpo normalizado". In: Espaço:informativo técnico-científico do INES. n. 8 (agosto-dezembro-1997) - Rio de Janeiro: INES, 1997.

SILVA, César Augusto de Assis. Cultura surda:agentes religiosos e a construção de uma identidade.São Paulo: Terceiro nome, 2012.

SILVEIRA, Rosa Hessel et All. A diferença na literatura infantil: narrativas e leituras. São Paulo: Editora Moderna, 2012.

STROBEL, Karin. As imagens do outro sobre a cultura surda. Florianópolis: Editora da UFSC, 2008.

SKLIAR, Carlos (Org.). A surdez: um olhar sobre as diferenças. Porto Alegre: Editora Mediação, 2013, 6ª Edição.

SKLIAR, Carlos. "A invenção e a exclusão da alteridade "deficiente" a partir dos significados da normalidade". In: Educação e Realidade. Porto Alegre, v. 24, n. ${ }^{2}$, jul./dez., 1999, p. 15-32.

STRNADOVÁ, Vera. Como é ser surdo. Tradução de Daniela Richter Teixeira. Petrópolis: Babel Editora, 2000.

VERGAMINI, Sabine Antonialli Arena (Org.). Mãos fazendo história. Petrópolis: Editora Arara Azul, 2003.

VILHALVA, Shilhey. Despertar do silêncio. Petrópolis: Editora Arara Azul, s/d,

WITT, Patrícia Rodrigues. Surdez: silêncio em voo de borboleta. Porto Alegre: Editora Movimento, 2013.

Paulo Roberto Tonani do Patrocínio é Doutor em Letras e Professor Adjunto do Departamento de Letras-Libras e do Programa de Pós-Graduação em Ciência da Literatura da Faculdade de Letras da UFRJ. É autor dos livros Escritos à margem: a presença de autores de periferia na cena literária brasileira (7Letras/FAPERJ, 2013) e Cidade de lobos: a representação de territórios marginais na obra de Rubens Figueiredo (Ed. UFMG/FAPERJ, 2016) e também co-organizador dos livros de ensaios Modos da margem, figurações da marginalidade na literatura brasileira (Aeroplano, 2015) e Estudos Culturais: legado e apropriações (Ed. Pontes, 2017). Atualmente desenvolve pesquisas sobre o conceito de diferença e representações e autorrepresentações da experiência surda e de sujeitos surdos. 